\title{
Study of thermal mechanical processing of modified epoxy matrixes and carbon fiber plastic on their basis
}

\author{
Nasonov Fedor Andreevich \\ Sukhoi Company: Departament of materials and \\ technologies \\ Moscow Aviation Institute \\ 125993, Volokolamskoe shosse, 4 \\ Moscow, Russia \\ Nasonovf2006@mail.ru
}

\author{
Bukharov Sergey Victorovich \\ Moscow Aviation Institute \\ 125993, Volokolamskoe shosse, 4 \\ Moscow, Russia \\ Bukharovsv@mail.ru
}

\begin{abstract}
The influence of the special modification of epoxy resins and polymer composites based on them on the basic properties of the composition is investigated. Modification is perform in order to reduce the damage during machining holes. The dependence of thermal effects of processes depending on the degree of modification is revealed.
\end{abstract}

Keywords-epoxy carbon plastic, modifier zinc stearate, pressure impregnation, autoclave molding, IR thermography

\section{INTRODUCTION}

Material science approach to solving the problems of achieving high technological and operational qualities of structures made of polymer composite materials is one of the main basis in the creation of new materials or improving already created. One typical example of this approach is the targeted modification of epoxy matrices and composites based on them. Thus, in the works $[1,2]$ as a target modifier, the authors applied surface-active substance (surfactant) zinc stearate, which is widely used in the technology of plastics and reinforced plastics as an anti-adhesive and anti-friction additives, as an "internal lubricant" in the processing of the fiberglass pultrusion method in the production of profile products to reduce friction between the walls of the working chamber pultruders and, to reduce the "breaking" of the filler fibers during the high pressure of the pultruders' profiling head in practically cured form, as well as to reduce the adhesive interaction between the material and the working metal surfaces of the pultruders and the profiling tools.

In this article about work, it is offered to apply this additive for the purpose of improvement of conditions of mechanical processing of already molded composite material. The study of the influence of the target modification on the thermophysical parameters of the processes in the formation of holes by machining in the details of carbon fiber polymer composite.

\section{OBJECTS AND METHODS OF RESEARCHING}

The objects of the study are the polymer composite material carbon fiber based on the following components: epoxy resin ED-20 in the system with curing agent Polyethylenepolyamine (PEPA), Zinc stearate modifier (SZ) (TU RF 2432-011-10269039-2013), unidirectional carbon fiber filler in the form of a tape carbon brand Porcher 14535. It should be emphasized that as a matrix material ("experimental model system"), a sufficiently well studied epoxy resin based on ED-20+PEPA is chosen, which is widely used in the aerospace industry to this day, but as components of adhesives, foaming fillers, etc. When creating new materials and modifying them, modern and promising high-tech matrix systems of complex compositions with outstanding performance characteristics should certainly be verified

Immediately after the addition of the modifier in the specified concentration ranges from $0 \%$ to $5.0 \%$ by weight in ED-20 resin to improve its distribution, samples of compositions were treated in an ultrasonic radiator with a capacity of 50 Watts for 15 minutes. Combination of compositions and filler was performed by the liquid-phase method (application and irrigation in specified quantitative ratios) [3], impregnation and subsequent molding of samples was carried out by vacuum-autoclave method. The mode of impregnation and molding was appointed in accordance with the typical technological parameters (for the "hot mode") system for the resin ED-20+PEPA [3 - 7]. The panels were manufactured to confirm the quality of non-destructive testing acoustic impedance method using the impedance defectoscope DAMI-C08 Converter type PADI-8 in accordance with PI RF 1.2.171-81. To confirm the mechanical properties of these panels were manufactured and tested on the test machine Instron 10T tensile specimens (GOST RF 25.601-80), compression (GOST RF 25.602-80), interlayer shear (OST RF 1 90199-75). For removal of thermal effects when machining in the digital processing center, the infrared thermographic camera with function of record of the Flir ThermaCAM model is used.

\section{MAIN PART}

In previous works [2, 7] the influence of ED-20+PEPA system modification and carbon fiber plastic based on it and on the main technological properties (resin viscosity, wetting ability, adaptability to high-quality impregnation of filler 
fibers, kinetic parameters of curing reaction, etc.) was studied. Non-destructive testing of experimental panels (Prot. № 3/onmk-33) was carried out and the main mechanical properties of carbon fiber based on the modified matrix were removed. The peace of view of the fragment of the manufactured panel is shown in figure 1. The main mechanical properties are shown in table 1 and figures 2 - 3 .

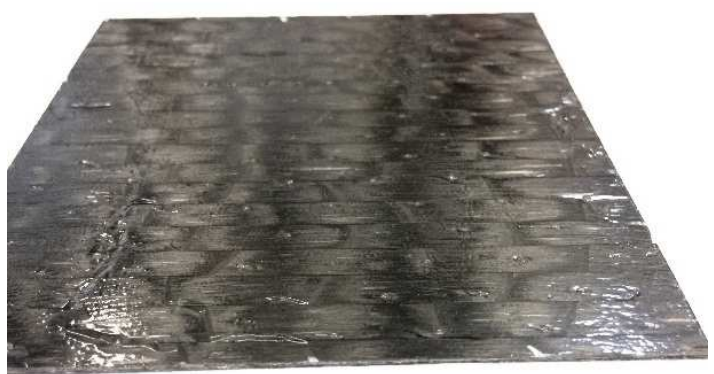

Fig. 1. The fragment of the experimental molded carbon panels (the number of layers is 10 , the scheme of reinforcement: $0^{\circ} / 90^{\circ}$ )

TABLE I. BASIC MECHANICAL PROPERTIES OF CARBON POLYMER COMPOSITE EXPERIMENTAL PANEL BASED ON MODIFIED MATRICES RECEIVED ON TEST RESULTS

\begin{tabular}{|c|c|c|c|}
\hline \multirow[t]{3}{*}{$\begin{array}{l}\text { Concentration of } \\
\text { modifier, \% } \\
\text { mass. }\end{array}$} & $\begin{array}{c}\text { Strength } \\
\text { tensile, MPa }\end{array}$ & $\begin{array}{c}\text { Strength } \\
\text { compression, } \\
\mathrm{MPa}\end{array}$ & $\begin{array}{l}\text { Strength at } \\
\text { interlaminar } \\
\text { shear, MPa }\end{array}$ \\
\hline & Min - $\max$ & Min - $\max$ & Min - $\max$ \\
\hline & Average values & Average values & Average values \\
\hline \multirow[t]{2}{*}{0} & $780-1224$ & $330-401$ & $23.7-27.5$ \\
\hline & 959 & 375 & 25.7 \\
\hline \multirow[t]{2}{*}{0.1} & $1042-1120$ & $453-627$ & \multirow{2}{*}{-} \\
\hline & 1081 & 554 & \\
\hline \multirow[t]{2}{*}{0.3} & 889-1356 & $353-471$ & 27.1-31.8 \\
\hline & 1043 & 428 & 29.3 \\
\hline \multirow[t]{2}{*}{0.5} & $1110-1412$ & $375-476$ & \multirow{2}{*}{-} \\
\hline & 1326 & 414 & \\
\hline \multirow[t]{2}{*}{1.0} & $1014-1351$ & $374-525$ & $30.6-33.1$ \\
\hline & 1174 & 460 & 31.6 \\
\hline \multirow[t]{2}{*}{5.0} & 928-1376 & $347-430$ & $17.9-22.3$ \\
\hline & 1196 & 376 & 20.4 \\
\hline
\end{tabular}

There are graphical dependences of mean values of strength of composite specimens under tension and under compression the concentration of the modifier in figure 2 .

It is shown that the modification of the epoxy matrix and structural carbon fiber composite on its basis, obtained by impregnation under pressure, followed by vacuum-autoclave molding in the concentration range of $0 . .5 .0 \%$ does not reduce the strength parameters for loads such as tension and compression. There is a decrease in strength at interlayer shear at concentrations approaching $5 \%$. For loads of tension and compression type, the maximum values are observed at 0.5 and $0.1-0.3 \%$, respectively.

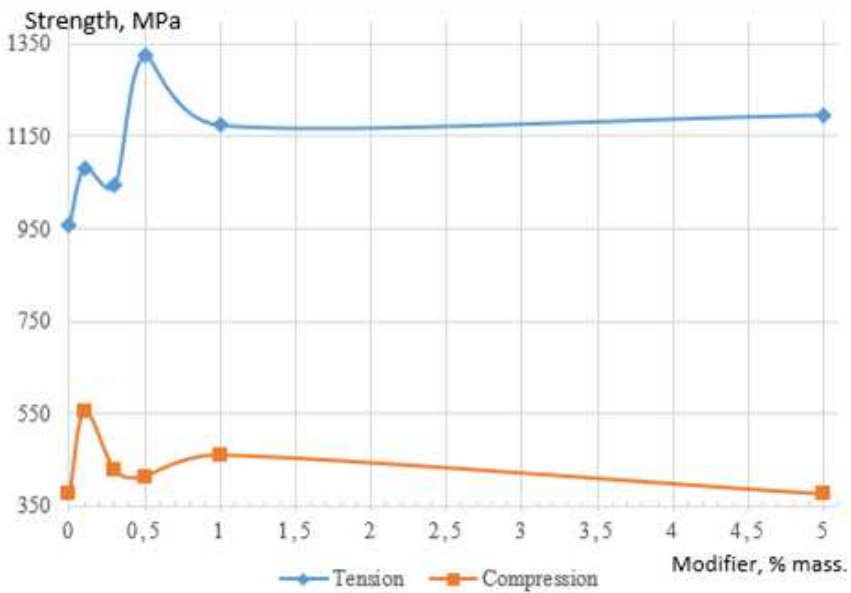

Fig. 2. Graphical dependences of mean values of strength of composite specimens under tension and under compression on the concentration of the modifier

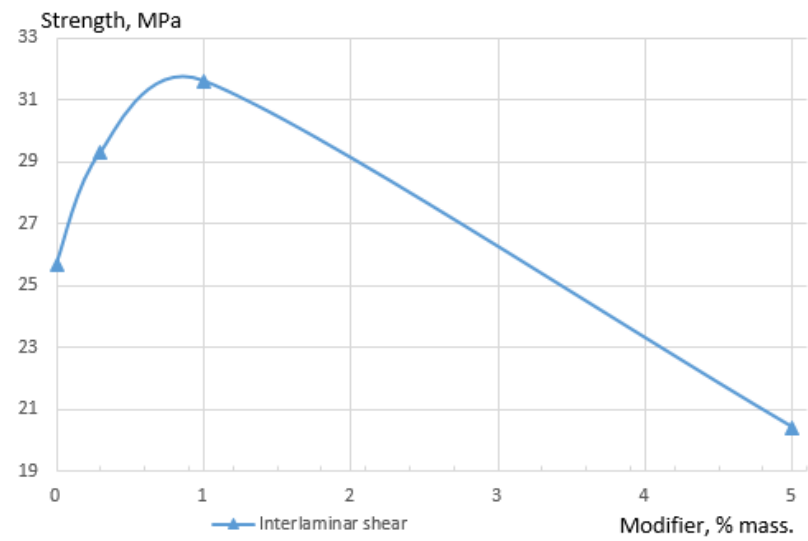

Fig. 3. Graphical dependences of mean values of strength of composite specimens under in interlaminar shear the concentration of the modifier

For comparative analysis of thermal effects during machining, the method of thermal nondestructive control in real-time machining of samples was used for the formation of holes.

On mechanical processing of samples in the form of plates with nominal dimensions of matrix samples obtained by casting without pressure, and molded samples of carbon fiber, a control program of the processing center with digital control for the formation of through holes with specified cutting conditions $(1000 \mathrm{rpm}, 30 \mathrm{~mm} / \mathrm{min})$ was completed. The formation of openings was carried out using three types of specialized tools: HSS drill, end mill tube type with mediumgrained diamond coated end mill HSS keyway-start. Air forced cooling and lubricating fluid supply have been shut down. Mechanical processing was carried out with the open doors of the center while ensuring compliance with safety requirements.

The implementation of temperature measurements in the machining of materials is a complex engineering task, which is due to a number of reasons. The main of them are the small size of the contacts on which thermal processes occur, the 
uneven distribution of temperature in depth and along the surfaces of contacting bodies, the very short period of existence and the random in time and space character of the appearance of single thermal sources [8 - 9]. In this study, a direct method of non-contact temperature measurement IR thermography [9 - 14] is applied. To relieve thermal effects during mechanical treatment used infrared thermal imaging camera with recording function model Flir ThermaCAM. The thermal imager was installed opposite the opened doors of the machining center along the axial machining line on a stationary tripod at a distance of $(1000 \pm 50) \mathrm{mm}$ from the machining zone.

Line of sight "viewfinder-lens-the blackened mark on the sample" was located at an angle $(30 \pm 5)^{\circ}$ (scheme in figure 4). The marks on the samples were applied previously in accordance with the control program to a depth of $0.5 \mathrm{~mm}$.in the samples (figure 5), Each row of the holes was carried out in series with the holding in the air of the tool and the workpiece and cleaning them. An example of a snapshot of the thermal pattern is shown in figure 6. After drilling the first hole in the row, the tool was not kept up to the initial temperature. Before the start of drilling, recording of a thermal picture with a shooting frequency of 1 Hertz was started.

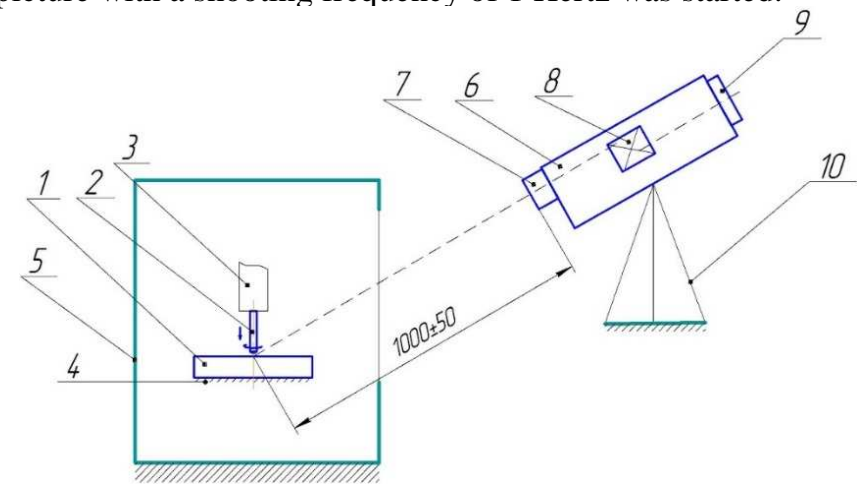

Fig. 4. The scheme of the measurement

1-test specimen; 2-working cutting tool; 3 -shaft; 4 - operational table of digital machine; 5 - base of digital machine; 6 - thermografic camera; 7 - lens; 8 - opto-digital converter; 9 - ocular; 10 - support.

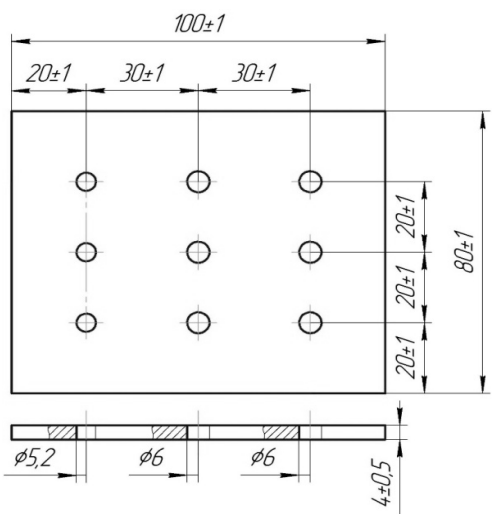

Fig. 5. The scheme of polymer matrix test specimen

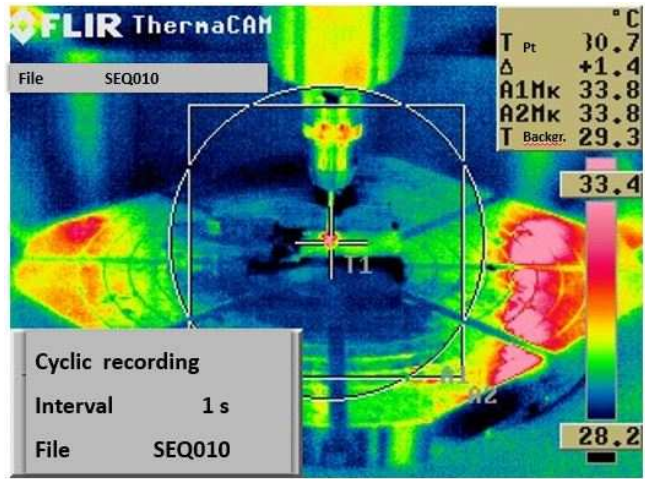

Fig. 6. An example of a snapshot of the thermal pattern

Tables 2 and 3 show the averaged maximum temperatures depending on the type of tool and the degree of modification of the epoxy matrix. Samples, the values of which are presented in table 2, are made by injection without pressure [2, 7]. Samples of carbon fiber reinforced plastics (table 3) produced by the method of impregnation under pressure and molding using the vacuum autoclave method [2, 7].

TABLE II. AVERAGED VALUES OF TEMPERATURE MAXIMA IN THE CUTTING ZONE DEPENDING ON THE TYPE OF TOOL AND THE DEGREE OF MODIFICATION OF THE EPOXY MATRIX

\begin{tabular}{|c|c|c|c|}
\hline \multirow{2}{*}{$\begin{array}{c}\text { Concent } \\
\text { ration of } \\
\text { modifier } \\
\text { \% } \\
\text { mass. }\end{array}$} & $\begin{array}{c}\text { Speed steel drill } \\
\text { dia 5.2 mm }\end{array}$ & $\begin{array}{c}\text { Type of tool steel } \\
\text { cutter dia 6.0 } \\
\text { mm }\end{array}$ & $\begin{array}{c}\text { Diamond tool dia 6.0 } \\
\text { mm }\end{array}$ \\
\cline { 2 - 4 } & \multicolumn{3}{|c|}{ Temperature, ${ }^{\circ}$ C } \\
\hline 0 & Tmax & Tmax & Tmax \\
\hline 0.1 & 52 & 85 & 95 \\
\hline 0.2 & 40 & 83 & 56 \\
\hline 0.3 & 37 & 50 & 60 \\
\hline 0.5 & 38.8 & 55 & 65 \\
\hline 1.0 & 45.3 & 70 & 80 \\
\hline 2.0 & 51 & 75 & 90.6 \\
\hline 3.0 & 56.5 & 80 & 90.5 \\
\hline 5.0 & 57 & 80 & 92 \\
\hline
\end{tabular}

Averaged temperatures in three consecutive measurements. Tstart $=28-30^{\circ} \mathrm{C}$. 
TABLE III. AVERAGED VALUES OF TEMPERATURE MAXIMA IN THE CUTTING ZONE DEPENDING ON THE TYPE OF TOOL AND THE DEGREE OF MODIFICATION OF THE EPOXY CARBON MATRIX

\begin{tabular}{|c|c|c|c|}
\hline \multirow{4}{*}{$\begin{array}{c}\text { Concent } \\
\text { ration of } \\
\text { modifier } \\
, \% \\
\text { mass. }\end{array}$} & \multicolumn{3}{|c|}{ Type of tool } \\
\hline & $\begin{array}{l}\text { Speed steel drill } \\
\quad \text { dia } 5.2 \mathrm{~mm}\end{array}$ & $\begin{array}{c}\text { Speed steel } \\
\text { cutter dia } 6.0 \\
\text { mm }\end{array}$ & $\begin{array}{c}\text { Diamond tool dia } 6.0 \\
\mathrm{~mm}\end{array}$ \\
\hline & \multicolumn{3}{|c|}{ Temperature, ${ }^{\circ} \mathrm{C}$} \\
\hline & $\operatorname{Tmax}$ & $\operatorname{Tmax}$ & $\operatorname{Tmax}$ \\
\hline 0 & 41.7 & 55.6 & 69.8 \\
\hline 0.1 & 30.5 & 56.6 & 51.6 \\
\hline 0.3 & 33.3 & 46.5 & 44.5 \\
\hline 0.5 & 32.5 & 36.1 & 46.3 \\
\hline 1.0 & 37.5 & 51.5 & 66.4 \\
\hline 5.0 & 53.3 & 54.3 & 71.2 \\
\hline
\end{tabular}

Averaged temperatures in three consecutive measurements. Tstart $=28-30^{\circ} \mathrm{C}$.

Figure 7 shows graphically the dependence of the temperature maxima on the modification degree and the type of tool for matrix and carbon-fiber samples.

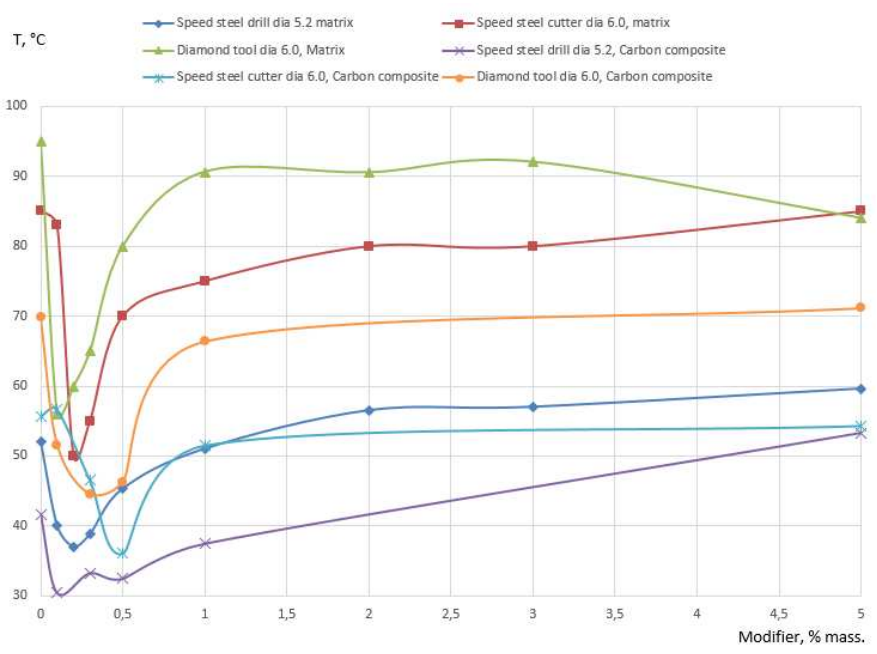

Fig. 7. Graphical representation of averaged (by three points) dependences of the temperature maximum of the hole formation process in matrix and carbon fiber samples. Lines for carbon fiber reinforced plastics are twice the thickness of the font

Lowest dissipation for the matrix samples were recorded in intervals of $0.1 \ldots 0.3 \%$ depending on the type of tool being used. For carbon-plastic samples based on modified matrices, the lowest heat release peaks are shifted slightly to the right in the range $0.2 \ldots 0.5 \%$. The decrease in the maximum temperatures in these ranges is explained by the antifriction properties of the SZ modifier: the friction properties and forces are reduced. Further increase in the modifier concentration leads to recovery or even exceeding the thermal effects relative to the initial unmodified matrices and carbon plastics $(0 \%$ SZ), which can presumably be explained by a decrease in cutting efficiency at reduced friction coefficients. The displacement of the peaks to the right and some of their "broadening" for carbon-plastic samples is probably due to the thermophysical properties of the filler, which change the conditions of heat removal from the contact zone of rubbing bodies (part and machining tool). In practice, it is carbon fiber that is of interest, as a composite combination of the matrix and the carbon filler, which, according to the results of these studies, has more favorable values of the thermal parameters of machining processes. At certain concentrations, for each type of matrix, the introduction of the modifier can serve as a basis for improving the conditions of machining, its intensification and reducing the number of micro-injuries. This circumstance will affect the quality of the formed holes, their accuracy and quality (including due to the reduction of thermal expansion).

\section{CONCLUSION}

A material science approach to change of physical and mechanical properties of semi-finished products and materials for processing in products, in particular by means of modification of matrices, makes it necessary to take into account possible influence of target additives on mechanical properties which cause suitability of materials to work in designs with the set indicators of safety, quality and reliability. The absence of negative influence of modification on mechanical properties of carbon fiber plastic on the basis of modified composition is shown. The revealed dependence of the thermal effects of the machining processes in the formation of holes in the samples the concentration of SZ modifier, which confirms the effectiveness of the modification.

\section{References}

[1] S.N. Korotkov, B.A. Zhovner, "Study on the method of DSK antiadhesive additives on the curing time of epoxy resins in the pultrusion process", Plasticheskie massy, No. 5, p. 46, 1991.

[2] F.A. Nasonov, "Issledovanie effektivnosti celevogo modificirovaniya ugleplastika I primeneniya stekloplastokovih vtulok pri reshenii problem mikropovregdaemosti kontrukcionnih ugleplastikov pri obrazovanii otverstii metodami mehanicheskoi obrabotki”, Itogi nauki, vol.32. pp. 64 - 82, October 2017 [All-Russian Conf. on new technologies, p. 133, 2017].

[3] I.P. Myichenko, Technology of semi-finished products of polymeric materials, SPb.: Scientific bases and technologies, 2012. pp. $120-132$.

[4] I.Z. Chernin, F.M. Laughter, Y.V. Zherdev, Epoxy polymers and compositions, Moscow: Chemistry, 1982, pp. 6-32.

[5] Yu.A. Mikhailin. Structural polymer composite materials. - SPb. scientific bases and technologies, 2008, pp. $124-154$.

[6] A. T. Tumanov, Aviation materials. A Handbook, in nine volumes Under the General editorship of corresponding member.-Corr. USSR Academy of Sciences A. T. Tumanov, vol. 9, Moscow: ONTI, 1973, pp. $43-56$.

[7] F. A. Nasonov, V. M. Aleksashin, D. A. Melnikov, S. V. Bukharov, "Issledovanie vliyaniya modificirovaniya epoxidnoi matricy I ugleplastika na eio osnove stearatom zinka na osnovniye tehnologicheskiye svoistva kompozicii”, Voprosy materialovedeniya, No. 3, pp. 20 - 26, 2018.

[8] A. Ersoy, S. Buyuksagic, U. Atici, "Wear characteristics of circular diamond saws in the cutting of different hard abrasive rocks", Wear, No. 258, pp. $1422-1436,2005$.

[9] P. N. Bogdanovich, D. V. Tkachuk, V. M. Belov, "Methods of temperature recording in friction and machining of solids", Journal of Friction and wear, No. 4, pp. $444-456,2006$. 
[10] P.C. Wanigarathne, A.D. Kardekar, O.W. Dillon, "Progressive tool-wear in machining with coated grooved tools and its correlation with cutting temperature", Wear, No. 259, pp. 1215 - 1224, 2005.

[11] B. Bhushan, Tribology and Mechanics of Magnetic Storage Devices, New York: Springer Verlag, 1990.

[12] H. T. Young, "Cutting temperature responses to flank wear", Wear, No. 201, pp. $117-120,1996$.
[13] J. Artozoul, Ch. Lescalier, O. Bomont, D. Dudzinski, "Extended infrared thermography applied to orthogonal cutting: Mechanical and thermal aspects", Applied Thermal Engineering, vol. 64, pp. 441 - 452, March 2014

[14] Yu.B. Minkin, S. V. Mikhailov, "Thermal imaging control of materials cutting process", Vestnik RGATA, No. 1, pp. 83 - 86, 2011. 